\title{
ASSESSMENT OF POSSIBILITY OF OBTAINING ALLOYING COMPONENTS IN THE PROCESS OF DESALTING OF HEAVY HYDROCARBON RAW MATERIALS. Part 2
}

\author{
B. Issa ${ }^{1}$, V. Yu. Bazhin ${ }^{1}$ \\ ${ }_{1}^{1}$ St. Petersburg Mining University (St. Petersburg, Russia) \\ E-mail: basharissashtain@gmail.com; bazhin-alfoil@mail.ru
}

\section{A UTHOR'S INFO \\ B. Issa, Post Graduate Student, Dept. of \\ Metallurgy, \\ V. Yu. Bazhin, \\ Dr. Eng., Prof., Head of \\ Dept. of Automation of \\ Technological Processes \\ and Production}

\section{A B S T RAC T}

Key words:

metal content oil, vanadium, nickel, sorption, desorption, recovery, electrodeposition, crude oil, naphthenic acid, resin, clay, glass, concentrate, hydrocarbon

Earlier, the authors had already successfully proposed a method for extracting minerals from crude oil as a first step, to be further developed in this second step in the direction of obtaining solid (metallic and / or oxide) phases of nickel and vanadium. The scientific, practical and strategic importance of the work is clearly-underlined with a general depletion of vanadium and nickel ores.

In the current situation of mineral resources with a general depletion of vanadium and nickel ores, it becomes necessary to search for new and alternative resources to obtain these strategic and important metals and their compounds from available resources. Taking into account that vanadium and nickel ores are practically absent in the raw material resources base of some countries, such as Middle East's countries. Thus, a high percentage of imports of this metal product remains, which worsens the economic situation that has developed during political conflicts.

The scientific approach was based on a combination of hydrometallurgical and electrometallurgical experiments, consistently carried out through the processes of sorption and desorption during cathodic electrodeposition. Sorption processes for vanadium and nickel were carried out using a mixture of Syrian sorbing materials (incense-type resins and surface-activated natural clays) with finely ground glass $\mathrm{SiO}_{2}$. Cathodic electrodeposition experiments were carried out on a copper cathode plate, and on the other hand, an insoluble glassy carbon electrode was used as the anode.

All batch experiments were carried out to determine the best conditions for vanadium and nickel sorption by studying six different parameters affecting the sorption capacity of vanadium and nickel. As a result, the maximum sorption capacity of vanadium and nickel was $87.5 \%$ and $91.3 \%$ consistently under the predetermined conditions. Eventually, $7.6 \% \mathrm{Ni}$ (with a purity of $97 \%$ ) was recovered from the solution after the desorption process by the electrolytic method (during electrolysis); $15.6 \%(99.3 \%$ pure $) \mathrm{V}_{2} \mathrm{O}_{5}$ and $11.5 \%(79 \%$ pure $) \mathrm{NiO}$ chemically.

\section{Introduction}

This article is a continuation of the work [1], in which the obtained results are presented about metals extraction from crude oil by its processing with naphthenic acid and water, followed by centrifugal separation to obtain hydrocarbon-metal containing concentrate.

Nowadays there is an increasing scientific and industrial interest in alloying elements (elements that are mainly added to control the properties of alloys) due to their role in producing improved alloys that meet industrial requirements and thus reduce economic losses. Alloying elements are used to improve the mechanical properties of steel alloys or to increase their corrosion resistance or thermal oxidation at high and/or low temperatures.

The most important raw materials for different industries are hydrocarbon raw materials and their residues [2-4]. In all over the world and in Russia especially, it has recently been observed: the continuous and increasing depletion of mineral reserves, the deterioration of the mining-geological and economic conditions for their exploitation and development with the noticeable reduction of geological exploration, taking into account that about half of the explored mineral deposits are not conditionally-profitable for development [5].
The production of heavy crude oils worldwide, which contain a significant amount of ferrous, non-ferrous and rare valuable metals (especially vanadium and nickel) is increasing rapidly. The high content of these metals allows us to consider hydrocarbon raw materials as a secondary and non-traditional resource for the recovery of these valuable metals [6-8], through their extraction; sorption on wide range of materials like, natural or modified clays; layered aluminosilicates; resins and / or by ionites; in addition to electrodeposition [9-12].

Analyzing metals concentration in two kinds of crude oils and their fuel oil residues (the residue of atmospheric distillation) proved that almost all metals passed to the fuel oil residue; while only vanadium, iron and nickel are accumulated in the fuel oil residue, and the content of aluminum and silicon is remained the same as in the crude oil of Usinsk and Yaregskoe, sequentially [13].

Some of the methods used for heavy crude oils processing are deasphalting process, hydrotreating (desalination and dehydration), delayed coking, demetallization and thermal destructive processes or gasification [14]. Hydrometallurgical process is highly important for producing low-impurity content oil products. Because it can lead to removal of metals, sulfur, and asphaltenes in parallel with improving the rheological properties [15-17]. 
In spite of the purpose of desalination and dehydration (preliminary preparation for crude oil) is to eliminate the harmful effect of water and salt contained in the crude oil [18]. Unfortunately, the multiple industrial problems in oil refineries and petrochemical plants confirm that these preliminary processes cannot completely solve the problem.

The trace metals in heavy crude oil (regardless of their quantities) - in addition to the content of chlorides, dissolved oxygen, dissolved carbon dioxide and sulfur negatively affect not only the quality of oil products and the environmental pollution, but also the performance of refining equipment (especially refrigerating-condensing and heat-exchange equipment, furnaces of rectification units etc.). Because they can easily and quickly interfere with upgrading processes; strongly poison a wide range of catalysts; catalyze harmful parallel reactions (carbonization); downgrade the remaining products (coke) in addition to its role in the corrosion, which can lead to premature failure of equipment, emergency stops, economic losses, and increased energy consumption [19].

The aim of this article is to take a further step in the same direction of our previous part by investigating the possibility to selectively recover solid (metallic and / or oxide) phases of nickel and vanadium.

\section{Research methods}

During the scientific research, the following equipment and methods were used. The XRF-1800 X-ray fluorescence spectrometer was used to determine the chemical composition of crude oil. The metal content and composition of the compounds passing into the aqueous phases after centrifugal separation from the organic phase were determined using an atomic emission spectrometer with inductively-coupled plasma ICPE 9000. The complex of combined thermogravimetric analysis and differential scanning calorimetry TGA / DSC1 NT MX1 were used for continuous recording the kinetic dependence of mass change on time and temperature, where the mass and heat are measured sequentially in relation to temperature changes to study the thermal stability and the changes that can occur to the components. The elemental composition of the sorbents was determined on a LECO-CHN628 analyzer. The gas chromatography mass spectrometer GCMS - QP2010 SE was used for thermogravimetric analysis and impurity detection.

\section{Research results and discussion - Selective sorption for vanadium and nickel from the obtained concentrate and their subsequent separation}

Today, sorption forms the basis of many industrial processes and scientific researches, which are particularly based on purification, isolation and separation of various materials, molecules and ions. Sorption and desorption processes in aqueous solutions have long been the subject of central interest in scientific research [20-24]. Despite the significant progress that has been made, sorption is still a very promising method due to its efficiency, ease, low cost, and abundance of sorbing materials, in addition to be an environmentally friendly method.

The traditional methods used for processing the oilwater emulsion can be classified into physical (sedimentation and flotation methods) and chemical (using of reagents). Unfortunately, in practice, both methods do not allow the separation to be completed to the desired quality [25]. Another method that has proven better results than the traditional methods was the use of magnetic processing for oil-water emulsion separation based on alternating magnetic field of low frequency, where the magnetic field in this case acts as an accelerator of the natural separation of the oil-water emulsion into its constituent ingredients [26].

Metal extracting from crude oil and oil products can be achieved via hydrometallurgical method by centrifugal separation in parallel with their purification from water, where the water phase together with the mechanical impurities are centrifugally-separated from the oil-phase [1, 27]. After processing West-Siberian crude oil by naphthenic acid and water followed by centrifugal separation (our previous work [1]), hydrocarbon metal-containing concentrate was obtained. For experiments, two-component Syrian sorbing mixtures were used: incense-type resin with finely-grinded glass and natural clay with finely-grinded glass for vanadium and nickel sequentially.

It should be noted that the resin was used without activation, while the clay was subjected to surface activation (characteristics of resin and clay have been carefully studied in our first part of this work). The glass (table 1) was prepared from collected broken laboratory glassware, which was grinded to a high degree $(800 \mu \mathrm{m})$. Chemical surface activation of the clay was carried out by using three solutions $(50 \mathrm{ml}, 1 \mathrm{M}$ (mol / L), $1 \mathrm{~g}$ clay) of $\mathrm{HCl}$, $\mathrm{H}_{2} \mathrm{SO}_{4}$ and $\mathrm{NaOH}$ separately under continuous stirring at room temperature for 24 hours. The sorption capacity of a standard solution of nickel chloride $(1 \mathrm{~N})$ was tested using each of these activated clays. According to the obtained

\begin{tabular}{|c|c|}
\hline Table 1. Composition of glass by XRF analysis \\
\hline Component & Weight percent, \% \\
\hline $\mathrm{SiO}_{2}$ & 91.7388 \\
\hline $\mathrm{NiO}$ & - \\
\hline $\mathrm{Na}_{2} \mathrm{O}$ & 4.6675 \\
\hline $\mathrm{Al}_{2} \mathrm{O}_{3}$ & 2.2036 \\
\hline $\mathrm{CoO}$ & - \\
\hline $\mathrm{K}_{2} \mathrm{O}$ & 0.8701 \\
\hline $\mathrm{SO}_{3}$ & - \\
\hline $\mathrm{CuO}$ & - \\
\hline $\mathrm{Cl}_{2}$ & 0.1251 \\
\hline $\mathrm{P}_{2}$ & 0.1198 \\
\hline $\mathrm{MgO}_{5} \mathrm{O}$ & - \\
\hline $\mathrm{Fe} \mathrm{O}_{3}$ & 0.1056 \\
\hline $\mathrm{CaO}$ & 0.0803 \\
\hline $\mathrm{TiO}_{2}$ & 0.0373 \\
\hline $\mathrm{PbO}^{\mathrm{ZrO}}$ & 0.0321 \\
\hline $\mathrm{Totally}_{2}$ & 0.0193 \\
\hline & 100 \\
\hline
\end{tabular}



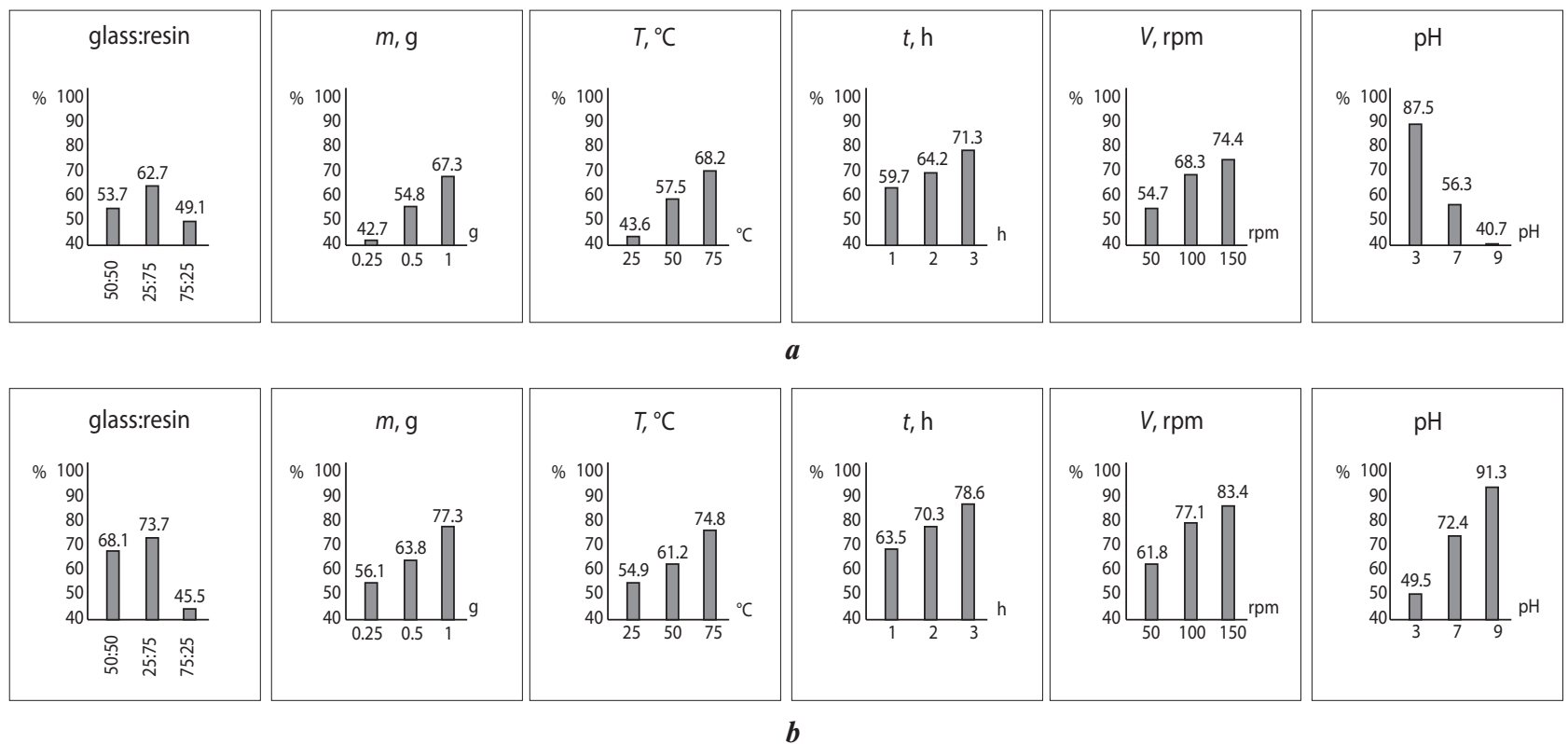

Fig. 1. Influence of mixing ratio; sorbing dose; temperature; contact time; stirring speed; and pH on the sorption capacity of: $a$ - vanadium and $b-$ nickel

results we found that the activated clay by $\mathrm{NaOH}$ has the highest sorption capacity compared to the activated clays by $\mathrm{HCl}, \mathrm{H}_{2} \mathrm{SO}_{4}(60 \%, 48 \%$ and $37 \%$ sequentially), which led to the use of the clay activated by $\mathrm{NaOH}$ for sorption experiments from the obtained concentrate.

It should be noted also that the used resin has a high molecular weight with a polymeric or semi-polymeric structure containing many aromatic rings (in which $\pi$-electrons are delocalized) in addition to many carboxyl functional groups.

The glass is likely to have a more deep functional role in the extraction process for the two metals. The hydrogen bonds between the $\mathrm{OH}$ groups of the terminal linkage $\mathrm{Si}-\mathrm{O}-\mathrm{Si}$ in glass and functional carboxyl groups (as substituents directly bonded to aromatic rings in the resin) can play a very important role to distract the ability of the electron-withdrawing groups «-M» of the carboxyl groups to withdrawing aromatic electrons, which increases the possibility of the formation of cation-aromatic $\pi$-electrons of the complex [28].

6 experiments were conducted to study 6 parameters affecting the sorption capacity of both vanadium and nickel, depending on changing only the value of one parameter in each experiment and keeping the value of the parameter that achieved the highest sorption capacity directly from the previous experiment in the subsequent experiments. Fig. 1 summarizes the results of the six experiments for both $\mathrm{V}$ and $\mathrm{Ni}$.

From fig. 1 we found that the mixing ratio of both components of the sorbents for vanadium and nickel was better when using one-third of the glass compared to the another sorbent for each of vanadium and nickel. As the glass dose increases, the sorption efficiency decreases, indicating that the role of the glass is not primary, but it has an additional or complementary role compared to another absorbent. Sorbent dose of $1 \mathrm{~g}$ leads to a sorption efficacy of just under $70 \%$ and $80 \%$ for both vanadium and nickel respectively. As the temperature increases, the sorption efficiency (capacity) of vanadium and nickel also elevates [29, 30]. The optimum contact time is $3 \mathrm{~h}$, with an increase in the sorption efficiency (capacity) of more than $70 \%$ for both vanadium and nickel separately. By increasing in the stirring speed by three times, the sorption capacity of both vanadium and nickel increases by $19.7 \%$ and $21.6 \%$, respectively.

The $\mathrm{pH}$ of the concentrate played a significant role in the sorption capacity of vanadium and nickel. We found that vanadium's sorption was preferable at a $\mathrm{pH} 3$; where the positively-charged dioxovanadium pentavalent vanadium cations $\mathrm{VO}_{2}^{+}$were dominant, while at $\mathrm{pH}$ 9, the negatively-charged pentavalent vanadate anions $\mathrm{VO}_{3}^{-}$ were dominant. The pentavalent vanadium cations can be preferably-engaged in cation-aromatic $\pi$ electrons interactions, which is the main reason that hold the obtained sorbed structure. While nickel sorption was preferable at pH 9 (where the surface-activated clay and the glass have a significant negative charge), as a result of the surface precipitation of nickel hydroxide $\mathrm{Ni}(\mathrm{OH})_{2}$ $(\downarrow)$ on the surface of the sorbing mixture due to its low solubility $\mathrm{Ni}(\mathrm{OH})_{2}\left(\mathrm{~K}_{\mathrm{sp}}=2,0 \times 10^{-15}\right)$ compared to $\mathrm{pH} 7$ or 3 . The disadvantage is the possibility of the accompanying precipitation of $\mathrm{Co}(\mathrm{OH})_{2}$ and $\mathrm{Fe}(\mathrm{OH})_{2}$ because of the convergence of their properties and solubilities $\left(\mathrm{K}_{\mathrm{sp}}=1.0 \times 10^{-15}\right.$ and $8.0 \times 10^{-16}$ sequentially $)$.

It should be noted that the separation of a mixture of two Syrian sorbents from each other [1] led to an increase in the sorption capacity of extracting nickel and vanadium compounds by $15.26 \%(91.3$ - 76) and $17.69 \%$ (87.5 - 69.8) respectively, in addition to activating the clay by $\mathrm{NaOH}$, adding finely ground glass to each of them separately and as a result of the six successive experiments to achieve the best conditions for sorption capacity. This 


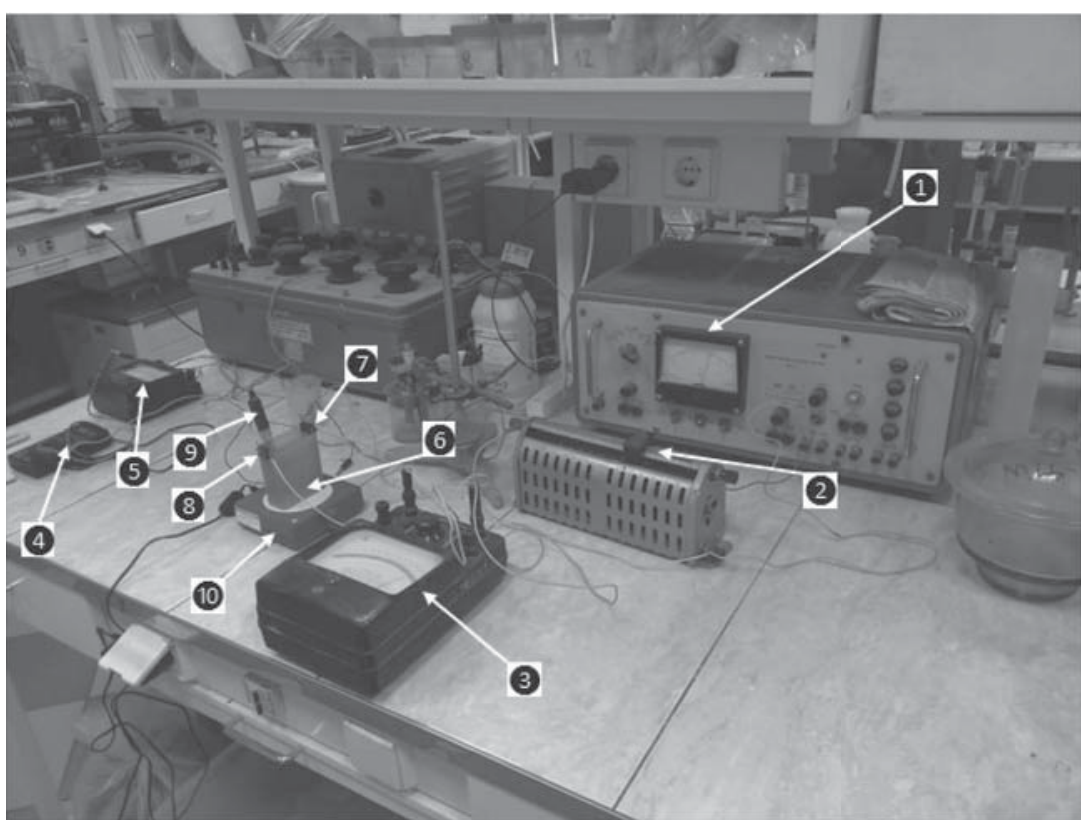

Fig. 2. Cathodic electro-deposition installation:

1 - power supply; 2 - variable resistance; 3 - current meter; 4-voltmeter; 5-galvanometer; 6 - metallic stirrer; 7 - cathode (copper plate); 8 - anode (glassy carbon electrode); 9 - reference electrode $(\mathrm{Ag} / \mathrm{AgCl}) ; 10$ - electromagnetic stirrer

is primarily due to the fact that the two Syrian sorbents differ in properties, just like vanadium and nickel, and, therefore, the interaction of each sorbent differs from the other, and thus the optimal conditions for the sorption of vanadium are different from nickel, in other words, each sorbent is more preferred for one of the two metals.

The role of glass in the extraction of nickel, especially at the last stage (study of $\mathrm{pH}$ ), is mainly associated with the dissociation of the $\mathrm{OH}$ groups of the terminal linkage $\mathrm{Si}-\mathrm{O}-\mathrm{Si}$ in glass at $9 \mathrm{pH}$.

$$
\underset{\mid}{\operatorname{Si}}-\mathrm{O}-\mathrm{H} \rightleftharpoons \underset{\text { | }}{\mid} \mathrm{Si}-\mathrm{O}^{-}+\mathrm{H}^{+}
$$

Regeneration (desorption) from the spent sorbents (for their further use) was carried out using $0.1 \mathrm{M} \mathrm{HCl}$ as desorbing agent in order to dissolve the precipitated nickel hydroxide from the sorbing mixture's surface and to break intermolecular interactions (to destroy pentavalent vanadium cation $\pi$-type complex), through the attraction of pentavalent vanadium cation by the chloride to form an intermediate compound $\mathrm{VO}_{2}^{+}+\mathrm{Cl}^{-} \rightarrow\left[\mathrm{VO}_{2} \mathrm{Cl}\right]$ that continues to interact with the hydrochloric acid as shown in the reaction $\left[\mathrm{VO}_{2} \mathrm{Cl}\right]+2 \mathrm{HCl} \rightarrow \mathrm{VOCl}_{3}+\mathrm{H}_{2} \mathrm{O}$ at room temperature and within 1 hour using a magnetic stirrer.

The mechanism of sorption of the pentavalent vanadium cation $\left(\mathrm{VO}_{2}{ }^{+}\right)$on the high-molecular structure of the resin is closely related to non-covalent interactions (due to complexation) with the formation of a non-covalent cation $\pi$-type complex, where aromatic $\pi$-electrons (in a polymer or semi-polymer resin) act as chelating agents. Whereas pentavalent vanadium does not have d-electrons to pair (co-participate) with $\pi$-electrons, a non-covalent bond is more likely because it requires less energy com- pared to a covalent bond (which, if it did, the desorption process would be more complex than what actually happened during desorption). In other words, if a covalent cation $\pi$-type complex is formed, the pentavalent vanadium cations would be so closely bound that their (cations) desorption would irreversibly damage the sorbent, proving that the resulting complex is non-covalent.

To recover vanadium and nickel from the obtained desorption solution, chemical and electrochemical experiments were conducted.

\section{Electrochemical experiment}

Electrochemical experiments were conducted to the desorption solution at room temperature by using inert (undissolved) electrode (glassy carbon electrode) as anode, copper plate as cathode and $\mathrm{Ag} / \mathrm{AgCl}$ reference electrode as shown in fig. 2. At the anode the following reaction took place: $2 \mathrm{Cl}^{-} \rightarrow \mathrm{Cl}_{2}+2 \mathrm{e}^{-}\left(\mathrm{E}^{\circ}=+1.36 \mathrm{~V}\right.$ ) (for $\mathrm{V}$ and $\mathrm{Ni}$ ). At the cathode we observed other reactions: $2 \mathrm{H}^{+}$ $+2 \mathrm{e}^{-} \rightarrow \mathrm{H}_{2}\left(\mathrm{E}^{\circ}=+0.00 \mathrm{~V}\right)$ (for $\mathrm{V}$ and $\mathrm{Ni}$ ); $\mathrm{VO}_{2}{ }^{+}+$ $+2 \mathrm{H}^{+}+\mathrm{e}^{-} \rightarrow \mathrm{VO}^{2+}+\mathrm{H}_{2} \mathrm{O}\left(\mathrm{E}^{\circ}=+1.001 \mathrm{~V}\right)$ (for $\mathrm{V}$ ); $\mathrm{Ni}^{2+}+2 \mathrm{e}^{-} \rightarrow \mathrm{Ni}\left(\mathrm{E}^{\circ}=-0.236 \mathrm{~V}\right)($ for $\mathrm{Ni})$.

Despite of our electrochemical experiments $-60 \mathrm{~mA} / \mathrm{cm}^{2}$ (for $\mathrm{V}$ and $\mathrm{Ni}$ ), $0.862-0.874 \mathrm{~V}$ (for $\mathrm{V}$ ), $0.657-0.662 \mathrm{~V}$ (for $\mathrm{Ni}$ - that lasted for 6 hours, they did not lead to the electrodeposition of vanadium as a metallic phase. However, these experiments were very important because they revealed to us the type of vanadium cation and its valence in the desorption solution by changing the color of the desorption solution during the electrochemical experiments from yellow (due to the presence of pentavalent vanadium (dioxovanadium) cation $\mathrm{VO}_{2}{ }^{+}$, through the green color (due to the mixture of their two colors) to the blue color (due to the tetravalent vanadium cation $\mathrm{VO}^{2+}$, according to the following reaction: $\mathrm{VO}_{2}{ }^{+}+2 \mathrm{H}^{+}+\mathrm{e}^{-} \rightarrow \mathrm{VO}^{2+}+\mathrm{H}_{2} \mathrm{O}$ $\left(\mathrm{E}^{\circ}=+1.001 \mathrm{~V}\right)$ [31].

While the nickel's deposited coating was examined by $\mathrm{X}$-ray phase analysis (table 2), scanning electron microscopy (fig. 3) and energy dispersive X-ray spectroscopy (table 3), which were used to analyze the structure, as well as the elemental and morphological composition of the coating [32]. Nickel and copper contents were about $20 \%$ and $80 \%$ sequentially (table 2 ). From a scientific point of view it is incorrect to talk about the purity of the nickel layer, for three reasons: 1) the high copper percent because the plate is from copper; 2) the copper plate itself contains impurities; 3 ) it is impossible to know the percent of the deposited copper from the desorption solution, because of all that, in order to determine the approximate (relative) nickel purity. 


\begin{tabular}{|c|c|}
\hline \multicolumn{2}{|c|}{ Table 2. XRF analysis for deposited-copper plate } \\
\hline Metal & Weight percent, $\%$ \\
\hline $\mathrm{Cu}$ & 80.0343 \\
\hline $\mathrm{Ni}$ & 19.5334 \\
\hline $\mathrm{Pb}$ & 0.2538 \\
\hline $\mathrm{Fe}$ & 0.1321 \\
\hline $\mathrm{Co}$ & 0.0308 \\
\hline $\mathrm{V}$ & 0.0157 \\
\hline Totally & 100 \\
\hline
\end{tabular}

Table 3. EDS analysis of the multi-element chemical composition of the plate

\begin{tabular}{|c|c|c|}
\hline Element & Weight, $\%$ & Atomic, $\%$ \\
\hline $\mathrm{O}$ & 6.45 & 20.67 \\
\hline $\mathrm{Cl}$ & 1.88 & 2.71 \\
\hline $\mathrm{Ni}$ & 40.27 & 35.15 \\
\hline $\mathrm{Cu}$ & 51.40 & 41.46 \\
\hline Totally & 100 & 100 \\
\hline
\end{tabular}

The obtained nickel coating was associated with high hydrogen evolution activity [33] as a result of morphological analysis (fig. 3) of the plate (by SEM Tescan Vega 3 $\mathrm{LMH}$ ), which the thin layer of nickel appears in a form of agglomerates (clusters) with cauliflower-like structure on matrix of copper in a form of grains with polygonal structure, surrounded by irregular channels and / or holes, formed as a result of the hydrogen evolution side reaction. Both of high current density and low $\mathrm{pH}$ of the desorption solution are responsible for the intensification of the hydrogen evolution side reaction on the copper cathode.

According to the atomic ratio (table 3) we have $35 \%$ $\mathrm{Ni}$ and $41 \% \mathrm{Cu}$. Theoretically we have about (50\% Ni: $50 \% \mathrm{Cu}$ ) sequentially, one atom of nickel should be electrodeposited on one copper atom. But practically, the percentage of nickel is slightly lower than the percentage of copper, which explains that the cathode electrodeposition of nickel did not reach to the end of the process.

Recovery of the electrodeposited nickel from the West-Siberian crude oil is $(6.27 / 82.5) \times 100=7.6 \% \mathrm{Ni}$ where $6.27 \mathrm{~g} / \mathrm{t}$ is the recovered nickel concentration and $82.5 \mathrm{~g} / \mathrm{t}$ is the nickel concentration in the crude oil.

\section{Hydrometallurgical chemical experiment}

In chemical experiments for vanadium; vanadium pentoxide was obtained as a result of hydrolysis and volatilization (by heating of the desorption solution). Combining the reactions $(\mathrm{III})+2 \times(\mathrm{I}+\mathrm{II})$, we will get the overall reaction during heating the desorption solution. But for nickel; nickel oxide was obtained by adding sodium hydroxide $\mathrm{NaOH}$ to the desorption solution, followed by filtering, washing and calcination at $400{ }^{\circ} \mathrm{C}$, where the deposition $\mathrm{pH}$ is 9 and 2 for nickel hydroxide and vanadium pentoxide, respectively. General reaction for $\mathrm{V}: 2 \mathrm{VOCl}_{3}+3 \mathrm{H}_{2} \mathrm{O} \rightarrow \mathrm{V}_{2} \mathrm{O}_{5}+6 \mathrm{HCl}$. Mechanism for $\mathrm{V}$ : first hydrolysis: $\mathrm{VOCl}_{3}+\mathrm{H}_{2} \mathrm{O} \stackrel{\Delta}{\longrightarrow} \mathrm{VO}_{2} \mathrm{Cl}+2 \mathrm{HCl} \uparrow$ (I); second hydrolysis: $\mathrm{VO}_{2} \mathrm{Cl}+\mathrm{H}_{2} \mathrm{O} \stackrel{\Delta}{\longrightarrow} \mathrm{HCl} \uparrow++\mathrm{HVO}_{3}$ (II); volatilization of $\mathrm{HCl}: 2 \mathrm{HVO}_{3} \stackrel{\Delta}{\longrightarrow} \mathrm{V}_{2} \mathrm{O}_{5} \downarrow+\mathrm{H}_{2} \mathrm{O} \uparrow$ (III).

The purity of vanadium pentoxide $\mathrm{V}_{2} \mathrm{O}_{5}$ chemicallyobtained from a desorption solution is about $99 \%$ (table 4)

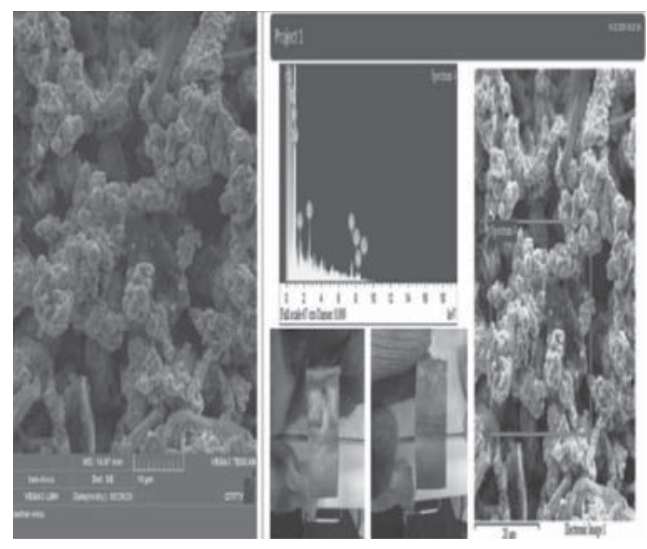

Fig. 3. Surface morphology of nickel layer electrochemicallydeposited and spectrum 4 of scanning electron microscope (3000x magnification) in addition to the copper plate after cathodic electrodeposition

with vanadium recovery of $[(3.92 / 25.1) \times 100]=15.6 \%$ $\mathrm{V}$ from the West-Siberian crude oil. While the purity of nickel oxide $\mathrm{NiO}$, chemically-obtained from a desorption solution (table 5) is about $79 \%$ with nickel recovery of $(9.46 / 82.5) \times 100=11.5 \% \mathrm{Ni}$ from the West-Siberian crude oil; where 3.92 and $9.46 \mathrm{~g} / \mathrm{t}$ - the recovered concentration for $\mathrm{V}$ and $\mathrm{Ni}$ sequentially and 25.1 and $82.5 \mathrm{~g} / \mathrm{t}$ - the concentration of $\mathrm{V}$ and $\mathrm{Ni}$ sequentially in the crude oil.

\begin{tabular}{|c|c|}
\hline $\begin{array}{l}\text { Table 4. Chemical composition of XRF analysis of chemically- } \\
\text { obtained } \mathbf{V}_{\mathbf{2}} \mathbf{O}_{\mathbf{5}}\end{array}$ \\
\hline Component & Weight percent, \% \\
\hline $\mathrm{V}_{2} \mathrm{O}_{5}$ & 99.3181 \\
\hline $\mathrm{Fe}_{2} \mathrm{O}_{3}$ & 0.2437 \\
\hline $\mathrm{SiO}_{2}$ & 0.0901 \\
\hline $\mathrm{P}_{2} \mathrm{O}_{5}$ & 0.0796 \\
\hline $\mathrm{ZnO}$ & 0.0728 \\
\hline $\mathrm{K}_{2} \mathrm{O}$ & 0.0723 \\
\hline $\mathrm{CaO}$ & 0.0534 \\
\hline $\mathrm{SO}_{3}$ & 0.0506 \\
\hline $\mathrm{Totally}$ & 100 \\
\hline
\end{tabular}

\begin{tabular}{|c|c|}
\hline \multicolumn{2}{|c|}{ Table 5. Composition of chemically-obtained NiO by XRF analysis } \\
\hline Component & Weight percent, \% \\
\hline $\mathrm{SiO}_{2}$ & 0.3604 \\
\hline $\mathrm{NiO}$ & 79.0190 \\
\hline $\mathrm{Na}_{2} \mathrm{O} \mathrm{O}_{3}$ & 8.4789 \\
\hline $\mathrm{CoO}$ & 0.2579 \\
\hline $\mathrm{K}_{2} \mathrm{O}$ & 1.0191 \\
\hline $\mathrm{SO}_{3}$ & - \\
\hline $\mathrm{CuO}$ & 0.3020 \\
\hline $\mathrm{Cl}$ & 0.1735 \\
\hline $\mathrm{P}_{2} \mathrm{O}_{5}$ & 9.3231 \\
\hline $\mathrm{MgO}$ & - \\
\hline $\mathrm{Fe}_{2} \mathrm{O}_{3}$ & 0.1155 \\
\hline $\mathrm{CaO}$ & 0.2722 \\
\hline $\mathrm{TiO}_{2}$ & 0.6784 \\
\hline $\mathrm{PbO}_{2 \mathrm{O} O}$ & - \\
\hline $\mathrm{Zrall}_{2}$ & - \\
\hline
\end{tabular}


As a result of calculations of the metallurgical balance, it was established that the extraction productivity is $5.1-13.1 \mathrm{~g} / \mathrm{t}$ $\mathrm{NiO}$ (with a content of 4-10.3 g/t of pure $\mathrm{Ni}$ ), and $8.4-25 \mathrm{~g} / \mathrm{t}$ $\mathrm{V}_{2} \mathrm{O}_{5}$ (with a content of $2.3-7 \mathrm{~g} / \mathrm{t}$ of pure $\mathrm{V}$ ) from the initial content of 35-90 g/t Ni and 15-45 g/t V, respectively, in the crude oil.

\section{Conclusions}

Maximum sorption capacity from hydrocarbon metalcontaining concentrate for vanadium and nickel were $87.5 \%$ [mixing ratio $25 \%$ glass: $75 \%$ resin (without activation), 1 g mixture weight, $75{ }^{\circ} \mathrm{C}, 3$ hours, $150 \mathrm{rpm}$ and $3 \mathrm{pH}$ ] and $91.3 \%$ [mixing ratio $25 \%$ glass: $75 \%$ clay (activated with $\mathrm{NaOH}), 1 \mathrm{~g}$ mixture weight, $75^{\circ} \mathrm{C}, 3$ hours, $150 \mathrm{rpm}$ and 9 $\mathrm{pH}$ ] sequentially.

Vanadium from the crude oil was chemically-recovered by $15.6 \%$ in the form of vanadium pentoxide $\mathrm{V}_{2} \mathrm{O}_{5}$ with a purity of $99.3 \%$ as a result of hydrolysis and volatilization of hydrogen chloride $\mathrm{HCl}$ (g) (by heating) of the obtained desorption solution. While $11.5 \%$ of nickel was chemicallyrecovered in the form of nickel oxide $\mathrm{NiO}$ with a purity of $79 \%$ by comparison with $7.6 \%$ of $\mathrm{Ni}$ from the crude oil was electrodeposited.

The better understanding of vanadium cations-aromatic $\pi$ interactions (in sorption-desorption processes) and the behavior of vanadium cations (during electrochemical experiments) is crucial for obtaining vanadium pentoxide with high purity. The interactions between pentavalent vanadium cations and aromatic $\pi$-electrons are mainly regulated by electrostatics, with a significant contribution of the $\mathrm{OH}$ groups of the terminal linkage $\mathrm{Si}-\mathrm{O}-\mathrm{Si}$ in glass through hydrogen bonds with functional carboxyl groups (substituents on the aromatic rings of the resin) to prevent or at least reduce the withdrawing of electron density, in addition to the very limited effect of pairing (co-participation) of electrons, which can be neglected.

The cauliflower-like morphology of the electro-deposited nickel layer is the inevitable result of vigorous hydrogen evolution side reaction on the cathode, because of high current density and low $\mathrm{pH}$ of the desorption solution (as a result of using hydrochloric acid as a desorbing agent).

\section{REFERENCES}

1. Issa B., Bazhin V. Yu., Aleksandrova T. A., Povarov V. G. Assessment of possibility of obtaining alloying components in the process of desalting of heavy hydrocarbon raw materials. Part 1. CIS Iron and Steel Review. 2020. Vol. 19. pp. 8-12.

2. Bujok P., Klempa M., Yakubchik M., RybaYa., Porzer M. Possibilities of open eruption elimination by drilling tools. Zapiski Gornogo instituta. 2018, Vol. 234. pp. 624-629.

3. Litvinenko V., Meyer B. Syngas Production: Status and potential for implementation in Russian industry. Springer International Publishing. 2017. 161 p.

4. Fetisov V., Pshenin V., Nagornov D., Lykov Y., Mohammadi A. H. Evaluation of Pollutant Emissions into the Atmosphere during the Loading of Hydrocarbons in Marine Oil Tankers in the Arctic Region. Journal of Marine Science and Engineering. 2020. Vol. 8. pp. $1-11$

5. Krasnov O. S., Salikhov V. A. The prospects evaluation of extraction of non-ferrous and rare metals reclaiming from ash-slag dumps of energy enterprises in Kemerovo region. Zapiski Gornogo instituta. 2013. Vol. 201. pp. 191-195.

6. Issa B., Aleksandrova T. A. Processes of Extraction of Non-Ferrous and Precious Metals from Alternative Sources of Raw Materials. IOP Conference Series Materials Science and Engineering. 2019. Vol. 582. pp. 234-243.

7. Kondrasheva N. K., Anchita J. Effect of chemical composition and quality of heavy yarega oil on selection of appropriate Processing Technology. Zapiski Gornogo instituta. 2016. Vol. 222 pp. 833-838.

8. Krasnov O. S., Salikhov V. A. Economical valuation of coal fields useful coproducts. Zapiski Gornogo instituta. 2013. Vol. 201. pp. 229-234.

9. Aleksandrova T., Aleksandrov A., Nikolaeva N. An Investigation of the Possibility of Extraction of Metals from Heavy Oil. Mineral Processing and Extractive Metallurgy Review. 2017. Vol. 38. No. 2. pp. 92-95.

10. Khalezov B. D., Gavrilov A. S. Petrova S. A., Ovchinnikova L. A. Nickel extraction from solutions using sodium hydrosulfide. $T s$ vetnye metally. 2019. No. 3. pp.33-38.

11. Sviridov A. V., Yurchenko V. V., Sviridov V. V., Ganebnykh E. V. Sorption of copper and nickel cations on layered aluminosilicates. Sorbtsionnye i khromatograficheskie protsessy. 2016. Vol. 16. pp. 78-86.

12. Lobko S. V., Kuzas E. A., Naboychenko S. S., Voinov V. N. Electrochlorination of secondary raw materials containing noble metals using bulk current lead. Tsvetnye metally. 2019. No. 3. pp. 45-49.

13. Kondrasheva N. K., Baitalov F. D., Boitsova A. A. Comparative assessment of structural-mechanical properties of heavy oils of timano-pechorskaya province. Zapiski Gornogo instituta. 2017. Vol. 225. pp. 320-329.

14. Kondrasheva N., Vasilyev V., Boytsova A. Research the possibility of obtaining high-quality petroleum coke from heavy Yaregskaya oil. Chemistry and Technology of Fuels and Oils. 2016. Vol. 6. pp. 14-18.

15. Anchita J. HYDRO-IMP Technology for Upgrading of Heavy Petroleum. Zapiski Gornogo instituta. 2017. Vol. 224. pp. 229-234.

16. Aleksandrova T. N., Romashev A. O., Aleksandrov A. V. About modeling of rheological properties of heavy oil suspensions. Neftyanoe Khozyaystvo. 2016. No. 5. pp. 68-70.

17. Aleksandrov A., Aleksandrova T., Romashev A. Modeling of motion of heavy oil suspensions with regard to rheological properties of liquid in a circular pipe. 17th International Multidisciplinary Scientific GeoConference Surveying Geology and Mining Ecology Management. , 2017. Vol. 17. pp. 729-734.

18. Kondrasheva N. K., Dubovikov O. A., Ivanov I. I., Zyryanova O. V. Preliminary preparation of oil for primary processing. Zapiski Gornogo instituta. 2014. Vol. 210. pp. 21-29.

19. Krasnyi V. A., Maksarov V. V., Olt Y. Application of polymeric composite materials in friction units of well oil pump. Zapiski Gornogo instituta. 2015. Vol. 211. pp. 71-79.

20. Zhu Huiwen, Xiao Xiyuan, Guo Zhaohui, Han Xiaoqing, Liang Yuqin, Zhang Yong, Zhou Cong. Adsorption of vanadium (V) on natural kaolinite and montmorillonite: Characteristics and mechanism. Applied clay science. 2018. Vol. 161. pp. 310-316.

21. Ordinartsev D. P., Sviridov A. V., Sviridov V. V. Extracting Vanadium, Molybdenum, and Tungsten from Acidic Solutions via Adsorption on Modified Montmorillonite. Zurnal fisicheskoy khimii. 2019. Vol. 92. pp. 2060-2064.

22. Zhu Xiaobo, Li Wang, Zhang Chuanxiang. Extraction and removal of vanadium by adsorption with resin $201 * 7$ from vanadium waste liquid. Environmental research. 2019. Vol. 180. pp. 1-6.

23. Troshkina I. D., Balanovskiy N. V., Nve Shvan Oo, Shilyaev A. V. Sorption of vanadium (V) from sulfuric-acid solutions by nanostructured nitrogen-containing ionites. Tsvetnye metally. 2013 No. 11. pp. 62-65.

24. Voropanova L. A., Pukhova V. P. Extraction of copper, cobalt and nickel ions from aqueous solutions by an extractant of the Suaneh brand 272. Zapiski Gornogo instituta. 2018. Vol. 233. pp. 498-505. 
25. Pashkevich M. A., Golubev I. A. Two-stage cleaning technology water out from oil. Zapiski Gornogo instituta. 2013. No. 203. pp. 83-85.

26. Pashkevich M. A., Golubev I. A. Development free-chemical method of cleaning waste water of a mineral-raw material complex. Zapiski Gornogo instituta. 2014. Vol. 207. pp. 199-201.

27. Grigorieva 1. V., Smirnov A. V., Roshchin G.S., Telyakov N. M. Application of centrifugal extractors in petrochemistry. Zapiski Gornogo instituta. 2006. Vol.169. pp. 111-112.

28. Plotnichenko V. G., Sokolov V. O., Dianov E.M.. Hydroxyl groups in high-purity silica glass. Journal of Non-Crystalline Solids. 2000. Vol.261. No. 1-3. pp.186-194.

29. Nazarova Z. M., Sobaev A. G., Zabaykin Yu. V. Efficiency of vanadium recovery during crude oil production. Gornyi Zhurnal. 2019. No. 11. pp. 60-62.

30. Vanore P., Coppola E., Iovino P., Leone V., Salvestrini S., Capasso S. Sorption thermodynamics of organic pollutants onto zeolitic tuff:
Isosteric and standard enthalpy. Journal of Water Chemistry and Technology. 2017. Vol. 39. pp. 228-232.

31. Zhen Jiang, Klyukin K., Alexandrov V. Structure, hydrolysis and diffusion of aqueous vanadium ions from Car-Parrinello molecular dynamics. The journal of chemical physics. Vol. 145., 2016, pp. $1-21$.

32. Illarionov I. E., Gilmanshina T. R., Kovaleva A. A., Bratukhina N. A.. Understanding the effect of structural defects in graphite on the properties of foundry coatings. CIS Iron and Steel Review. 2018. Vol. 16. pp. 63-66.

33. Kiryukhantsev-Korneev F. V., Sytchenko A. D., Kudryashov A. E., Levashov E. A. Protective coatings produced by electro-spark deposition with $\mathrm{TiCNiCr}-\left(\mathrm{Eu}_{2} \mathrm{O}_{3}\right)$ electrodes. CIS Iron and Steel Review. 2018. Vol. 16. pp. 57-62.

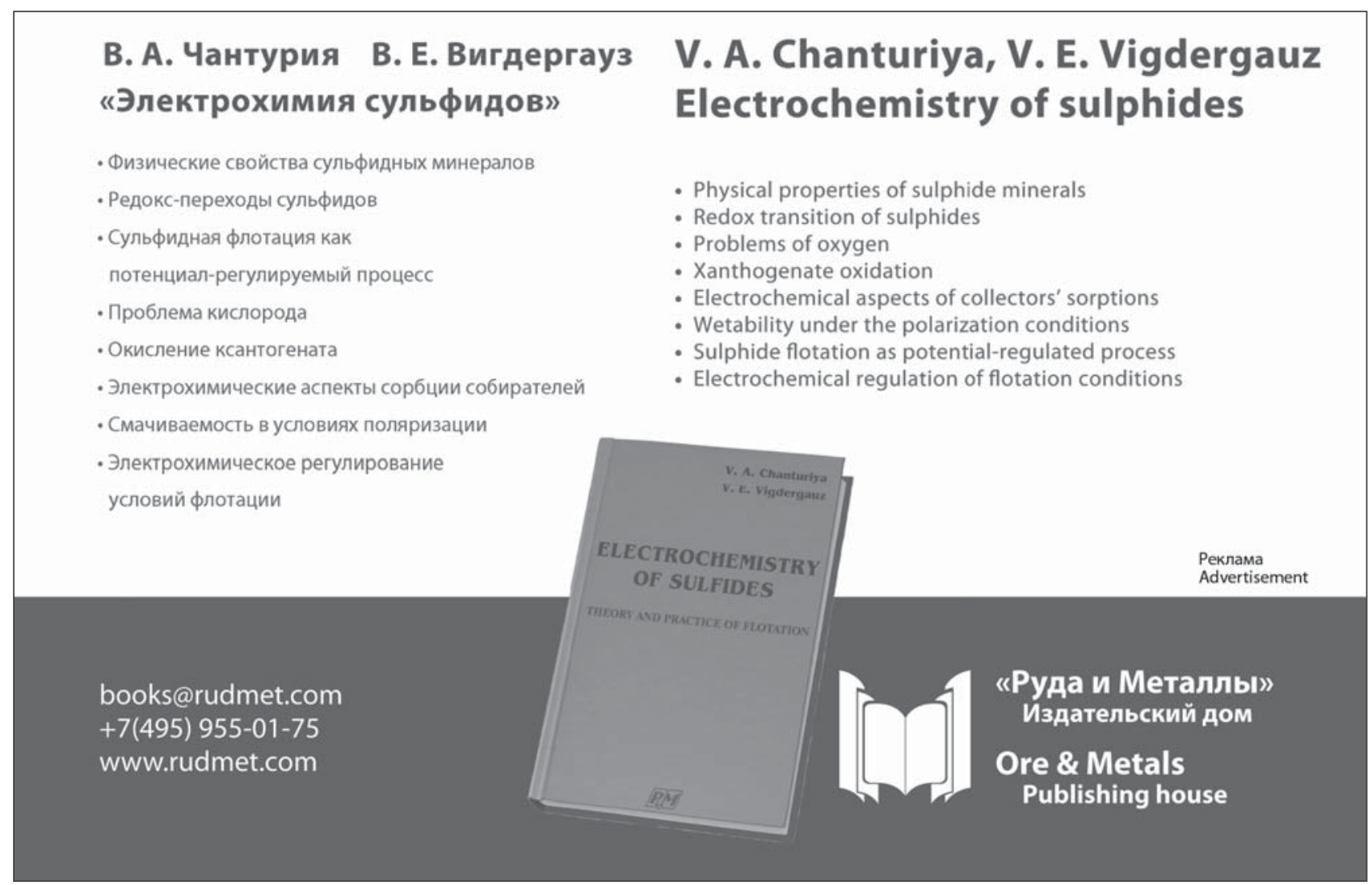

